\title{
Pathology of colorectal adenomas: a colonoscopic
} survey

\author{
F KONISHI, BC MORSON
}

From the Department of Pathology, St Mark's Hospital, City Road, London ECIV 2PS

SUMMARY The size, histological type, and grade of dysplasia of a large series of colorectal adenomas removed by colonoscopic polypectomy were matched against other variables such as anatomical site, age, sex, and number of adenomas per patient. Special emphasis was placed on the criteria for grading dysplasia in adenomas and the possible significance of severe dysplasia as a selective marker for increased colorectal cancer risk. The results showed that small adenomas (mostly with mild dysplasia) were evenly distributed throughout the colorectum but that adenomas showing severe dysplasia (mostly the larger tumours, $>10 \mathrm{~mm}$ diameter) were concentrated in the left colon and rectum, particularly the sigmoid part which is also the segment with the highest risk of colorectal carcinoma in high risk populations.

Severe dysplasia in adenomas appears to be a selective histopathological marker for increased colorectal cancer risk. It is closely linked with increasing age and numbers of adenomas per patient, with the larger adenomas and particularly those with a villous component in their histology. Severe dysplasia and multiple adenomas could be valuable markers for selecting from the total adenoma population those most deserving of close surveillance in follow-up cancer prevention programmes.

Conceptually it would appear advantageous to think in terms of the dysplasia-carcinoma sequence in the colorectum rather than the polyp-cancer or adenoma-carcinoma sequence. The implications of these results in the study of the aetiology of colorectal cancer are discussed.

The increasing role of colonoscopy and polypectomy in the diagnosis and management of colorectal adenomas during the past decade has provided the histopathologist with an abundance of valuable material for study. This material is especially useful because, in most patients subjected to colonoscopy, the entire colorectum has been visualised at one examination and all polyps removed for histological diagnosis. Previous studies have relied on adenomas removed by proctosigmoidoscopy only, and surgical segments of bowel usually removed for carcinoma in which adenomas were a coincidental finding. Therefore, a colonoscopic survey should provide more detailed information about their distribution in the large bowel matched against other variables such as size, histological type, and grades of dysplasia. The results of such a clinical survey can then be compared with the figures given in various necropsy.

Accepted for publication 16 December 1981 reports. Emphasis in this study is also placed on the significance of grade of dysplasia, and especially severe dysplasia because the latter has been established as a valuable marker for increased cancer risk in ulcerative colitis as well as in the study of the epidemiology of adenomas.

\section{Material and methods}

During the eight-year period 1972 to 1979,1167 adenomas were removed by colonoscopy from 675 patients (398 men and 277 women) either by snare polypectomy or the hot-biopsy-fulguration method. ${ }^{1}$ The histological sections for 28 adenomas were missing, leaving 1139 adenomas available for study. From the same 675 patients a further 102 adenomas were removed by other methods, mostly by rigid proctosigmoidoscopy but a few by surgical excision. These were also included in the study, making a total of 1241 examined. Of these, 54 showing microinvasive carcinoma were excluded thus leaving a final total of 1187 adenomas for analysis. 
All the removed adenomas were fixed in buffered $10 \%$ formaldehyde solution; the position of the stalk was identified, if possible, and the specimens were embedded on their sides in paraffin wax so that the tumour and stalk were orientated in their correct anatomical relationship to one another. In small adenomas $(<0.5 \mathrm{~cm}$ diam $)$, only one level was cut; in larger adenomas however two or more levels were taken, according to the size of the specimen. Multiple semiserial sections were cut only in a minority of specimens to assess questionable examples of microinvasive carcinoma. All sections were stained by haematoxylin and eosin.

Size was measured on the histology slides in two dimensions and the arithmetic mean was calculated to represent the size of the tumours. Comparison of size measured in the fresh state and on histological slides showed that the size on the section was the same as, or only slightly smaller than, that in the fresh state because of the method of embedding the tumours. All the sections were examined by one of the authors (FK) and graded according to histological type and grade of dysplasia (see later).

The site of adenomas was identified from the colonoscopy records. The large bowel was divided into five segments: right colon (caecum and ascending colon); transverse colon; descending colon; sigmoid colon; rectum. If indicated as splenic flexure or hepatic flexure, tumours at these sites were evenly allocated to either of the two adjacent segments. Age and sex of the patients were checked in the colonoscopy records or in the patients' notes.

Removal of rectal polyps by rigid proctosigmoidoscopy is often performed in the Outpatient Clinic or operating theatre rather than by colonoscopic polypectomy. In addition, removal of adenomas by proctosigmoidoscopy may have been performed at other hospitals before the patients attended St Mark's. For these reasons accurate comparison of the number of rectal and colonic adenomas was not possible. In order to make a proper comparative study of size, histological type, and grades of epithelial dysplasia between rectal and colonic adenomas a separate consecutive series of 270 rectal adenomas removed by rigid proctosigmoidoscopy during the four-year period 1976 to 1979 was also studied.

Almost all the patients in the colonoscopy series had barium enema study before colonoscopy either at St Mark's Hospital (St Mark's patients) or at other hospitals (cases referred only for colonoscopy). In referred cases when barium enema failed to visualise particular segments of colon (usually the right side), total colonoscopy was carried out but

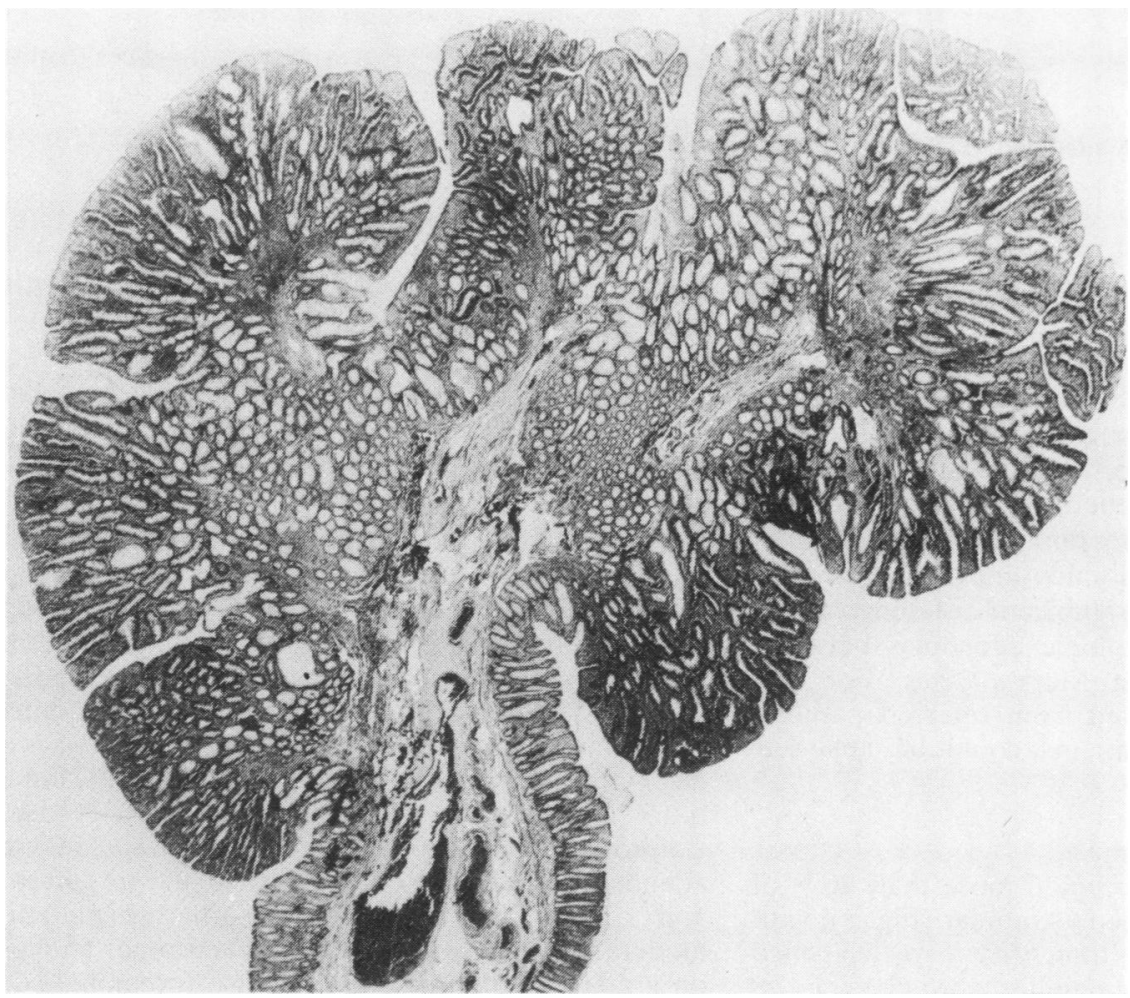

Fig. 1 Tubular adenoma. Haematoxylin and $\operatorname{eosin} \times 10$. 


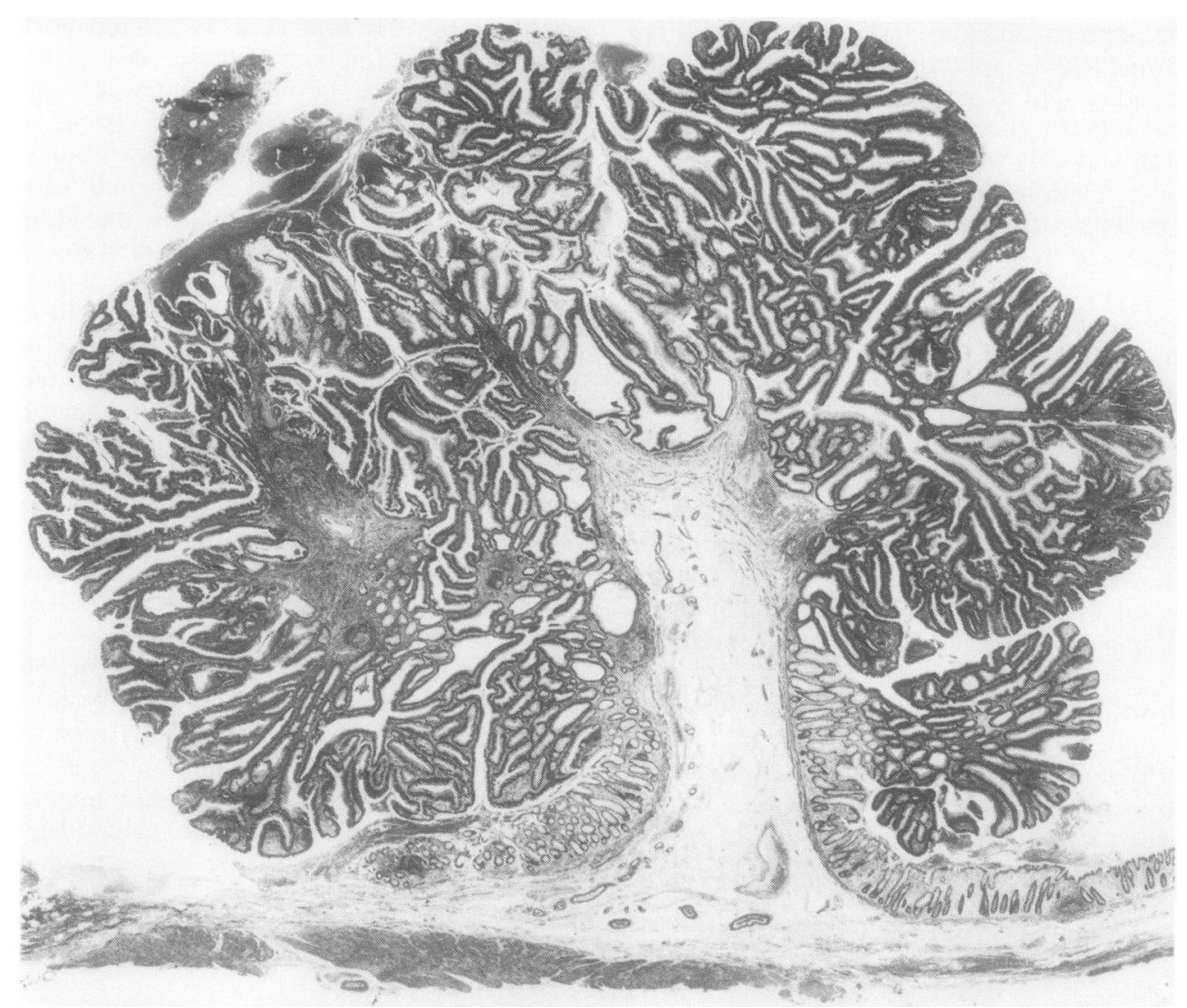

Fig. 2 Tubulovillous adenoma. Haematoxylin and eosin $\times 10$.

when the barium enema study was of sufficient quality and no polyps were seen in the right colon, total colonoscopy was not invariably performed. Using this policy total colonoscopy was performed in $60 \%$ of the cases and 601 patients were considered to have had adequate total examination of the large bowel by barium enema study and fibreoptic colonoscopy. There was no significant difference in the subsite distribution of colonic adenomas between "referred cases" and St Mark's cases. For this reason adenomas removed from referred patients and from St Mark's patients could be analysed together.

\section{HISTOLOGY OF ADENOMAS}

If the tubular pattern occupied more than $80 \%$ of the tumour it was classified as tubular (Fig. 1); with a villous pattern of more than $80 \%$ it was classified as villous (Fig. 2); the remainder were classified as tubulovillous (Fig. 3).

Irrespective of histological type all adenomas can be graded by histological and cytological criteria into three grades of epithelial dysplasia (atypia)mild, moderate, and severe, the latter being used synonymously with carcinoma-in-situ. However, there are reasons for avoiding the use of this term in surgical reports. ${ }^{2}$ It is common to see differing grades of dysplasia within any one adenoma and in this study individual adenomas have been graded according to the part with the most advanced grade. Sometimes an area with one grade of dysplasia has a distinct boundary with the adjacent area showing a different grade but more often there is a gradual transition. A focus of severe dysplasia in an adenoma often shows an expansive growth pattern and a sharp boundary with the adjacent mild to moderate dysplasia. There have been other studies on grading dysplasia ${ }^{3-6}$ but it must be emphasised 


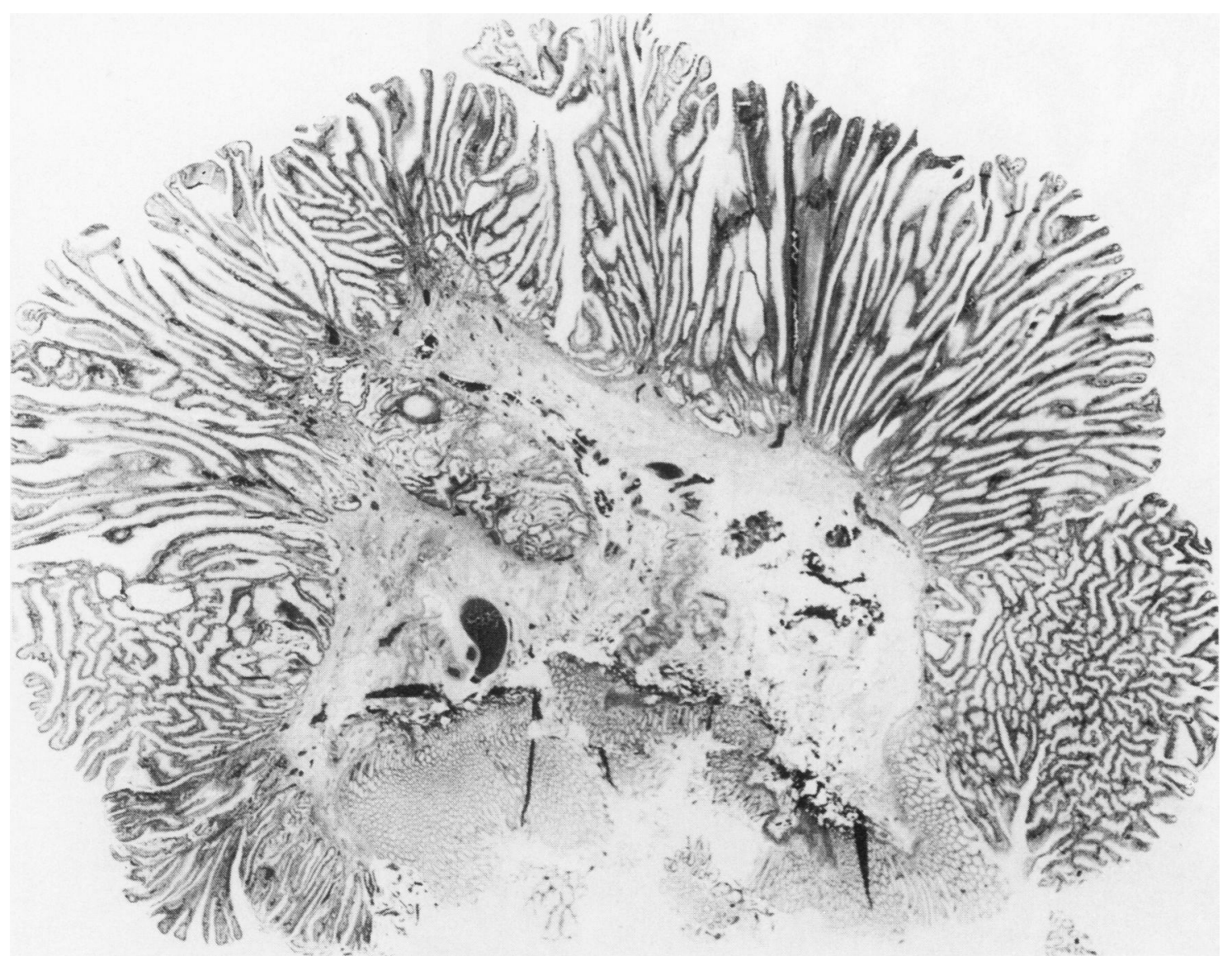

Fig. 3 Villous adenoma. Haematoxylin and eosin $\times 10$.

that grading is a subjective assessment taking both structural and cytological changes into consideration.

\section{GRADING OF DYSPLASIA}

\section{Mild dysplasia (Fig. 4)}

The nuclei are elongated, larger than normal and slightly hyperchromatic with a fine chromatin pattern. They are arranged regularly at the base of the cells. Usually nucleoli are not seen. The amount of mucin is decreased and is confined to the lumenal border of the cells. The number of mitotic figures is slightly increased. Pleomorphism and loss of polarity of the nuclei are not typical features of this category. The glandular arrangement is irregular with some branching but there is no further disorganisation of the glandular structure. Only occasional reversed goblet cells (intraepithelial goblet cells) may be seen. The distinction from moderate dysplasia becomes blurred when the nucleoli begin to become stratified with some loss of polarity and the amount of mucin is further decreased.

\section{Moderate dysplasia (Fig. 5)}

This category can be defined as intermediate between mild dysplasia and severe dysplasia. The nuclei are elliptical rather than elongated and the chromatin is denser and tends to show a clumping pattern. There is nuclear pseudostratification and minor loss of polarity with some increase in the nuclear-cytoplasmic ratio. The amount of mucin is further decreased and reversed goblet cells are seen more often. An important change is the tendency towards pleomorphism of nuclei. The interglandular space is reduced and structural distortion of the crypts is more manifest, with folding of epithelial cells into the glandular lumen. This is different from the true intraglandular budding and bridging which are the features of severe dysplasia. 


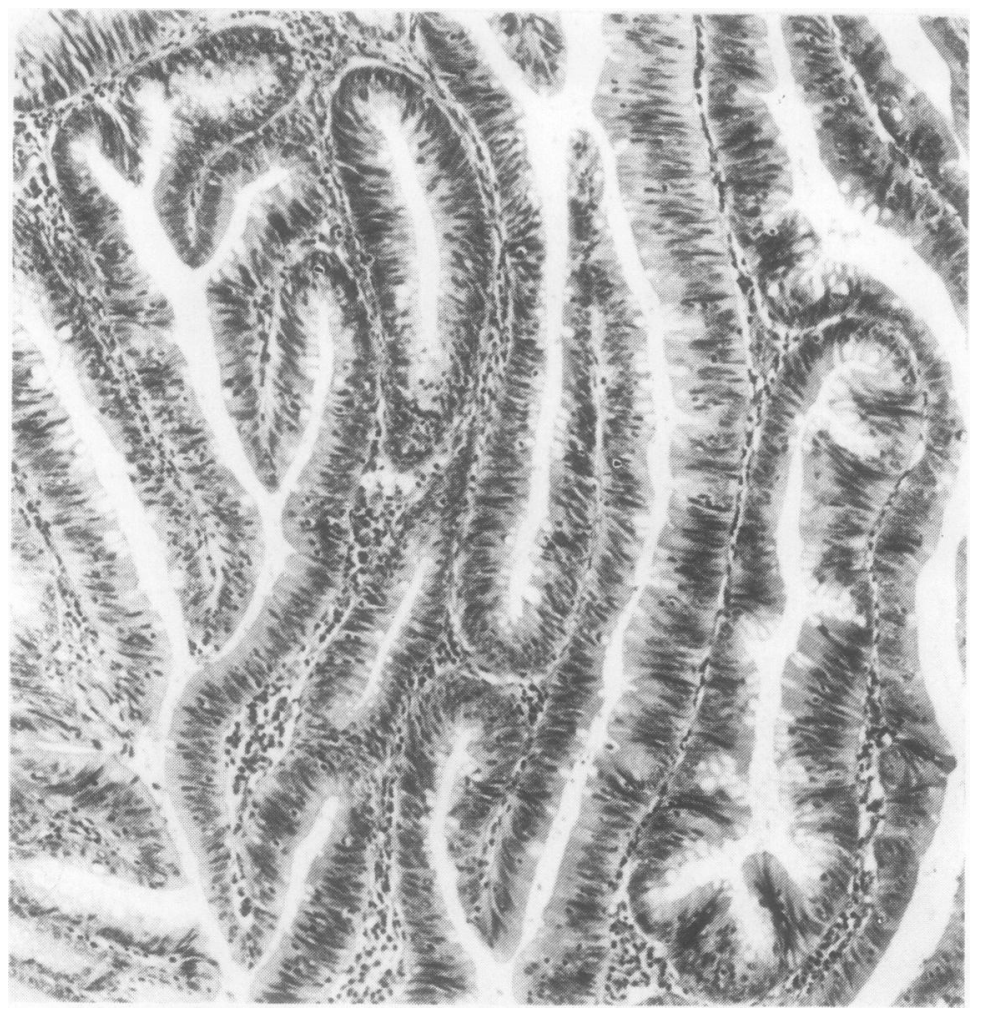

Fig. 4 Mild dysplasia. Nuclei are regularly arranged on the basal side of the glands. There is some branching of the glands. Mucin is relatively well preserved.

Haematoxylin and eosin $\times 120$.

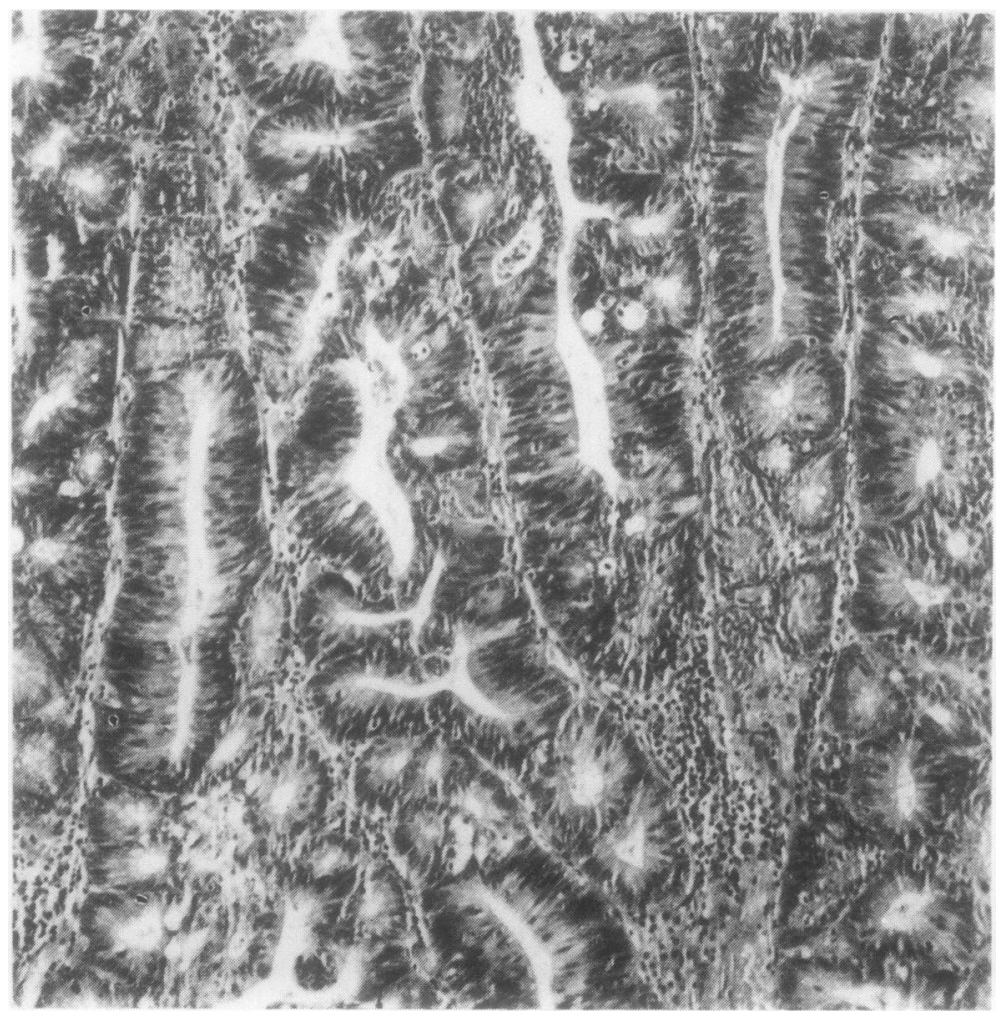

Fig. 5 Moderate dysplasia. Nuclei are larger and show

pseudostratification. Mucin is decreased. There is moderate structural abnormality.

Haematoxylin and eosin $\times 120$. 


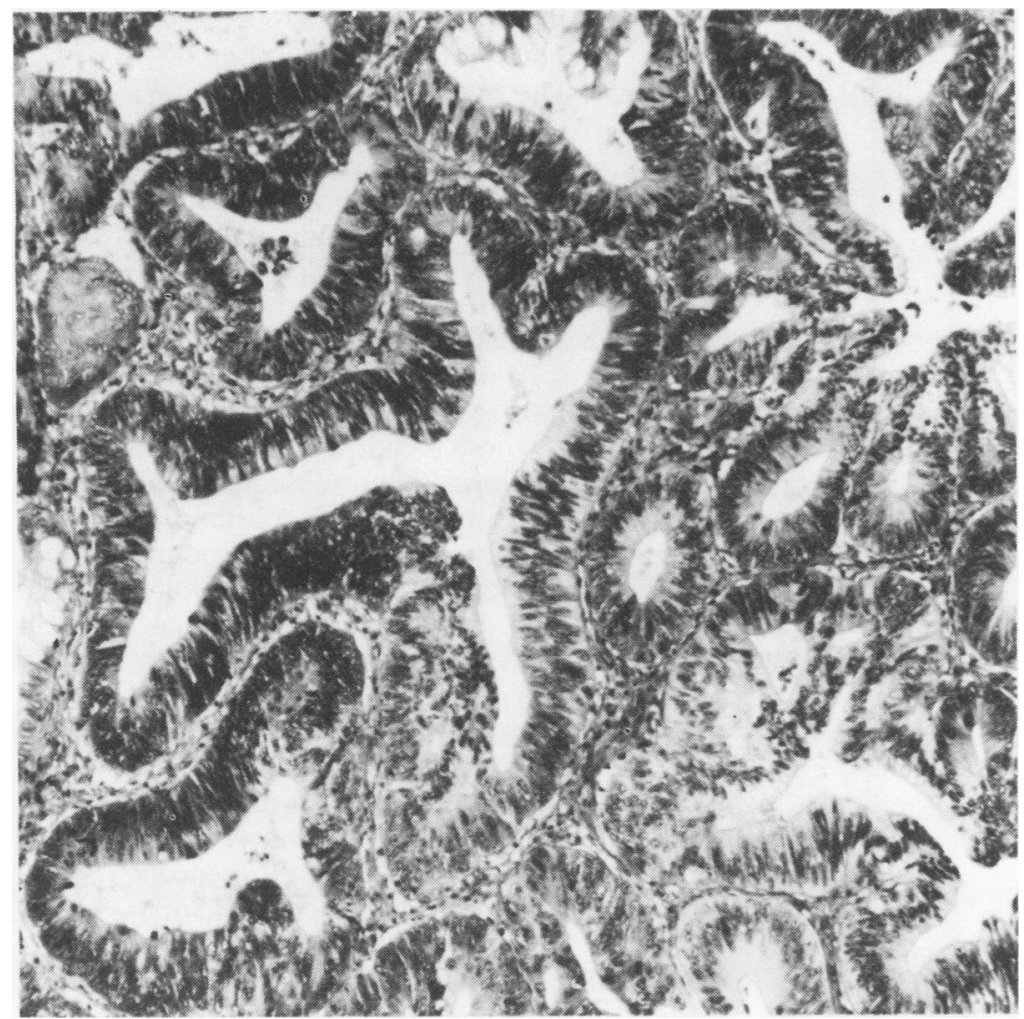

Fig. 6 Severe dysplasia.

Nuclei are pleomorphic and show loss of polarity. Structural abnormality is marked, featuring intraglandular budding and bridging. Haematoxylin and eosin $x$ 120.

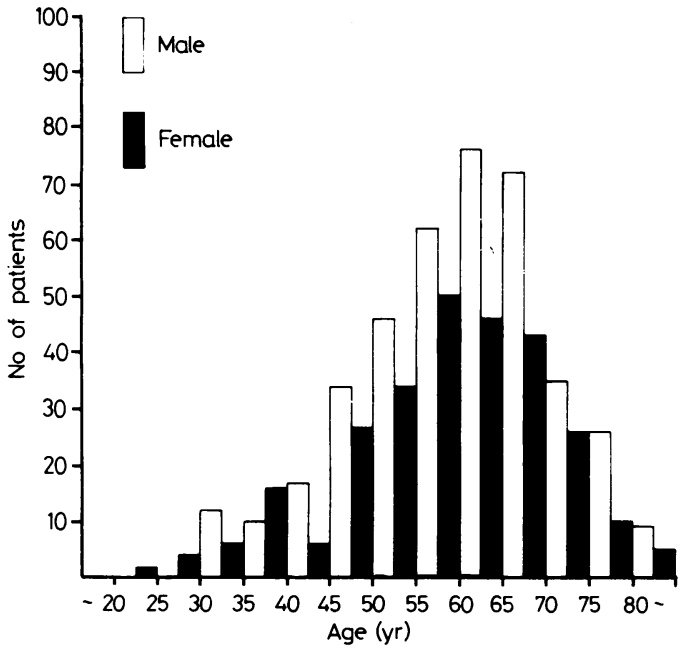

Fig. 7 Age and sex distribution of 675 patients.

Severe dysplasia (Fig. 6)

The changes are very similar to those of invading adenocarcinoma. The nuclei are large and pleomorphic with an obvious increase in the nuclear-cytoplasmic ratio. The chromatin pattern is either diffusely dark or open with clumping of the chromatin and one or more nucleoli can often be seen. The marked pleomorphism is associated with loss of polarity of the nuclei and an obvious increase in the number of mitotic figures. These are the most important features of this category. Little mucin is present and cannot be recognised as a clear droplet with haematoxylin and eosin staining. The glandular structure is very distorted featuring frequent intraglandular bridging and budding with obliteration of the interglandular space, which gives the impression of glandular fusion. This condensed growth pattern is the so-called "glandular back-to-back" arrangement. In some cases, despite little evidence of intraglandular budding and bridging, the nuclei are large and show severe pleomorphism and loss of polarity. In many adenomas areas of severe dysplasia have a distinct boundary with adjacent less severe, even mild, changes.

\section{Results}

\section{AGE AND SEX DISTRIBUTION}

Figure 7 shows the age and sex distribution of the 675 patients in this series. The mean ages were $61 \cdot 1$ $\mathrm{yr}$ for men and 59.1 yr for women. The peak inci- 


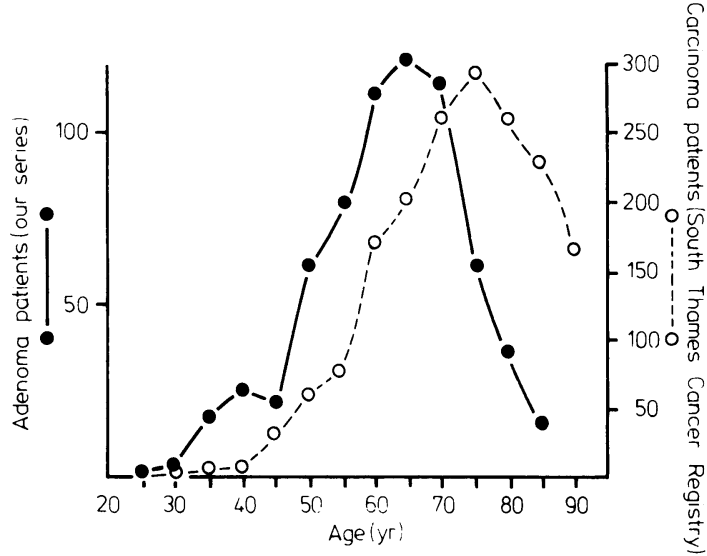

Fig. 8 Age distribution of adenoma patients (this series) and carcinoma patients (South West Thames Cancer Registry). ${ }^{7}$

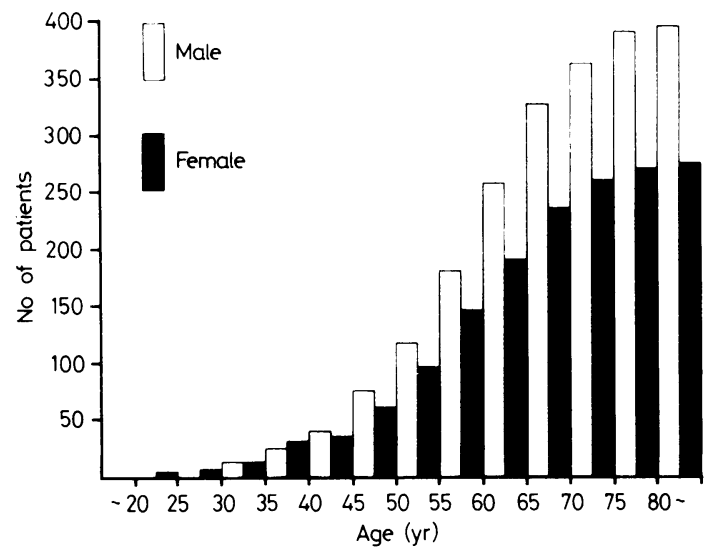

Fig. 9 Cumulative age and sex distribution.

dence for men is in the age group 60-65 $\mathrm{yr}$ and for women is in the 55-60 yr group. Compared to the age distribution of large bowel carcinomas, ${ }^{7}$ the peak incidence occurs about 10 years younger in our adenoma patients than in carcinoma patients (Fig. 8), a figure which lends support to the concept of the adenoma-carcinoma sequence.

Figure 9 shows the cumulative age and sex distribution; the number of younger women patients slightly predominates, or is about the same as that of younger men patients but as age increases from 50 $\mathrm{yr}$ to over $80 \mathrm{yr}$, the tendency is for men patients to predominate. This tendency is similar to that of the age-sex distribution of large bowel carcinoma in high-risk countries, as reported by Haenszel and Correa. $^{8}$
DISTRIBUTION AND SITE OF ADENOMAS

Table 1 shows the site distribution of 1187 adenomas. The number of rectal adenomas should not be compared to the number in the colon because, as described previously, rectal adenomas are often treated separately from colonic adenomas. About half $(47 \%)$ of adenomas removed were located in the sigmoid colon, the percentage decreases from the sigmoid proximally to the right colon $(8.2 \%)$ in striking contrast to the distribution of adenomas in necropsy series. ${ }^{9-14}$ The figure for the right colon could be a slight underestimate because of those endoscopically irremovable adenomas not biopsied and subsequently treated by right hemicolectomy. Most reports of necropsy studies show a more or less even distribution with a slightly greater percentage in the right colon. It must be remembered, however, that adenomas found in necropsy studies were mostly smaller than those in our colonoscopic series.

Table 2 shows the size of 1187 adenomas by site. Colonic adenomas smaller than $5 \mathrm{~mm}$ show a comparatively even distribution but in striking contrast those measuring 5 to $10 \mathrm{~mm}$ and $>10 \mathrm{~mm}$ are concentrated in the left colon; the difference is statistically highly significant. $\left(\chi^{2}=162 \cdot 17\right.$, df $=8, p<$ 0.001.)

A similar trend has been shown in other studies. ${ }^{113}$ The percentage of rectal adenomas measuring 6-10 $\mathrm{mm} \mathrm{(29 \% )}$ and $>10 \mathrm{~mm} \mathrm{(23 \% )} \mathrm{are}$ less than those of sigmoid colon adenomas within the same size group (approximately 39\% for both). However, it should be mentioned that broad-based adenomas often measuring $3.0 \mathrm{~cm}$ across or even larger are more common in the rectum than in the sigmoid colon or descending colon. In the right colon and in the transverse colon, $67 \%$ of adenomas were $<5 \mathrm{~mm}$ diameter excluding a small number of

Table 1 Distribution of adenomas (combined series)

\begin{tabular}{llllll}
\hline $\begin{array}{l}\text { Right } \\
\text { colon }\end{array}$ & $\begin{array}{l}\text { Trans } \\
\text { colon }\end{array}$ & $\begin{array}{l}\text { Desc } \\
\text { colon }\end{array}$ & $\begin{array}{l}\text { Sigmoid } \\
\text { colon }\end{array}$ & Rectum & Total \\
\hline $\begin{array}{l}8.2 \% \\
(97)\end{array}$ & $\begin{array}{l}13.6 \% \\
(161)\end{array}$ & $\begin{array}{l}18.7 \% \\
(222)\end{array}$ & $\begin{array}{l}47.0 \% \\
(559)\end{array}$ & $\begin{array}{l}12.5 \% \\
(148)\end{array}$ & $\begin{array}{l}100 \% \\
(1187)\end{array}$ \\
\hline
\end{tabular}

Table 2 Size and site (1187 adenomas)

\begin{tabular}{lllllll}
\hline Size & $\begin{array}{l}\text { Right } \\
\text { colon }\end{array}$ & $\begin{array}{l}\text { Trans } \\
\text { colon }\end{array}$ & $\begin{array}{l}\text { Desc } \\
\text { colon }\end{array}$ & $\begin{array}{l}\text { Sigmoid } \\
\text { colon }\end{array}$ & Rectum Total \\
\hline$<5 \mathrm{~mm}$ & $64.0 \%$ & $69.2 \%$ & $44.6 \%$ & $22.2 \%$ & $48.0 \%$ & $39.3 \%$ \\
& $(62)$ & $(111)$ & $(99)$ & $(124)$ & $(71)$ & $(467)$ \\
$6-10 \mathrm{~mm}$ & $18.5 \%$ & $17.4 \%$ & $31.1 \%$ & $38.8 \%$ & $29.0 \%$ & $31.6 \%$ \\
& $(18)$ & $(28)$ & $(69)$ & $(217)$ & $(43)$ & $(375)$ \\
$>10 \mathrm{~mm}$ & $17.5 \%$ & $13.4 \%$ & $24.3 \%$ & $39.0 \%$ & $23.0 \%$ & $29.1 \%$ \\
& $(17)$ & $(22)$ & $(54)$ & $(218)$ & $(34)$ & $(345)$ \\
\hline
\end{tabular}


large irremovable ones. Larger adenomas in the sigmoid colon and rectum may be detected more readily than large adenomas located in other parts of the large bowel because of easier accessibility to endoscopic examination.

\section{SITE AND GRADE OF DYSPLASIA}

Table 3 shows the relation between the grade of dysplasia and the site. The most striking difference is the high percentage $(9.5 \%)$ of severe dysplasia in the left colon; $68 \%$ of adenomas with severe dysplasia are located in this part of the colorectum. Adenomas with moderate dysplasia, although more often seen, show a similar subsite distribution as adenomas with severe dysplasia. The difference is statistically highly significant. $\left(\chi^{2}=44 \cdot 19, \mathrm{df}=8, \mathrm{p}\right.$ $<0.001$.)

The percentage of each grade of dysplasia in the rectum is more or less similar to that obtained from the series of all rectal adenomas removed at St Mark's Hospital from 1976 to 1979 (Table 4) and in this series similar to that in the descending colon. The unexpectedly small percentage of severe dysplasia in the right colon and rectum could be due to biased selection of patients.

\section{HISTOLOGICAL TYPES OF ADENOMA}

The majority of adenomas $(81 \%)$ were classified as tubular; $16 \%$ as tubulovillous (intermediate) and only $3 \%$ as villous adenoma (Table 5). Except for the percentage of villous adenomas, these figures are not significantly different when compared with a previous report from this hospital. ${ }^{6}$ The smaller percentage of villous adenomas in this study compared to the surgical series reported by Muto et al is probably due to the fact that in this colonoscopic series there was a smaller number of rectal adenomas.

It has been stated that villous adenomas are located almost exclusively in the rectum. ${ }^{1516}$ In contrast, our study has shown that both tubulovillous and villous adenomas are more widely distributed with only a slightly higher incidence in the rectum and in the sigmoid colon. The percentage in the right colon, although not significantly different, is slightly higher than in the transverse and the descending colon. Again, the data for tubulovillous and villous adenomas of the rectum in this colonoscopy series (including adenomas removed by other methods) are similar to those for the previous surgical series of rectal adenomas removed at St Mark's Hospital from 1976 to 1980 (Table 6).

Table 7 shows the percentage of the three histological types related to the age of patients. The percentage of tubulovillous and villous adenomas is greater among patients older than $70 \mathrm{yr}$ compared
Table 3 Percentage grades of dysplasia by site (1187 adenomas)

\begin{tabular}{lllllll}
\hline Grade & $\begin{array}{l}\text { Right } \\
\text { colon }\end{array}$ & $\begin{array}{l}\text { Trans } \\
\text { colon }\end{array}$ & $\begin{array}{l}\text { Desc } \\
\text { colon }\end{array}$ & $\begin{array}{l}\text { Sigmoid } \\
\text { colon }\end{array}$ & Rectum & Total \\
\hline Mild & $94.9 \%$ & $90.7 \%$ & $86.0 \%$ & $74.8 \%$ & $84.5 \%$ & $81.9 \%$ \\
& $(92)$ & $(146)$ & $(191)$ & $(418)$ & $(125)$ & $(972)$ \\
Moderate & $4.1 \%$ & $8.1 \%$ & $8.1 \%$ & $15.7 \%$ & $10.1 \%$ & $11.6 \%$ \\
& $(4)$ & $(13)$ & $(18)$ & $(88)$ & $(15)$ & $(138)$ \\
Severe & $1.0 \%$ & $1.2 \%$ & $5.9 \%$ & $9.5 \%$ & $5.4 \%$ & $6.5 \%$ \\
& $(1)$ & $(2)$ & $(13)$ & $(53)$ & $(8)$ & $(77)$ \\
\hline
\end{tabular}

Table 4 Grades of dysplasia in rectal adenomas

\begin{tabular}{llll}
\hline & Mild & Moderate & Severe \\
\hline Rectal adenomas in & $84.5 \%$ & $10 \cdot 1 \%$ & $5.4 \%$ \\
colonoscopic series & $(125)$ & $(15)$ & $(8)$ \\
All rectal adenomas & $82.2 \%$ & $12 \cdot 6 \%$ & $5 \cdot 2 \%$ \\
$(1976-1979)$ & $(222)$ & $(34)$ & $(14)$ \\
\hline
\end{tabular}

Table 5 Histological type by site (1187 adenomas)

\begin{tabular}{lllllll}
\hline Type & $\begin{array}{l}\text { Right } \\
\text { colon }\end{array}$ & $\begin{array}{l}\text { Trans } \\
\text { colon }\end{array}$ & $\begin{array}{l}\text { Desc } \\
\text { colon }\end{array}$ & $\begin{array}{l}\text { Sigmoid } \\
\text { colon }\end{array}$ & Rectum & Total \\
\hline Tubular & $83.5 \%$ & $89.4 \%$ & $85.5 \%$ & $78.8 \%$ & $69.6 \%$ & $80.7 \%$ \\
& $(81)$ & $(144)$ & $(190)$ & $(440)$ & $(103)$ & $(958)$ \\
Tubulo- & $14.4 \%$ & $9.9 \%$ & $11.7 \%$ & $18.2 \%$ & $25.0 \%$ & $16.4 \%$ \\
villous & $(14)$ & $(16)$ & $(26)$ & $(102)$ & $(37)$ & $(195)$ \\
Villous & $2.1 \%$ & $0.6 \%$ & $2.7 \%$ & $3.0 \%$ & $5.4 \%$ & $2.9 \%$ \\
& $(2)$ & $(1)$ & $(6)$ & $(17)$ & $(8)$ & $(34)$ \\
\hline
\end{tabular}

Table 6 Histological type of rectal adenomas

\begin{tabular}{llll}
\hline & Tubular & Tubulovillous & Villous \\
\hline Rectal adenomas in & $69.6 \%$ & $25.0 \%$ & $5.4 \%$ \\
colonoscopic series & $(103)$ & $(37)$ & $(8)$ \\
All rectal adenomas & $70.7 \%$ & $23.0 \%$ & $6.3 \%$ \\
$(1976-1979)$ & $(191)$ & $(62)$ & $(17)$ \\
\hline
\end{tabular}

Table 7 Histological type and age (1187 adenomas)

\begin{tabular}{llll}
\hline Type & $<50 y r$ & $51-70 y r$ & $>71$ yr \\
\hline Tubular & $84.6 \%$ & $81.9 \%$ & $73.4 \%$ \\
Tubulovillous & $(171)$ & $(621)$ & $(166)$ \\
& $12.4 \%$ & $15.9 \%$ & $21.7 \%$ \\
Villous & $(25)$ & $(121)$ & $(49)$ \\
& $3.0 \%$ & $2.2 \%$ & $4.9 \%$ \\
& $(6)$ & $(17)$ & $(11)$ \\
\hline
\end{tabular}

to younger age groups. This difference is statistically significant. $\left(\chi^{2}=9.04, \mathrm{df}=4,0.01<\mathrm{p}<0.02.\right)$

It may be contributing to the observation that the percentage of severe dysplasia in patients older than $70 \mathrm{yr}$ is greater than that in the younger age groups.

GRADE OF DYSPLASIA AND HISTOLOGICAL TYPE The percentage of the different histological types in relation to degree of dysplasia shows that as the his- 
Table 8 Percentage grades of dysplasia by histological type (1187 adenomas)

\begin{tabular}{lllll}
\hline Grade & Tubular & Tubulovillous & Villous & Total \\
\hline Mild & $\mathbf{8 8 . 2 \%}$ & $57.9 \%$ & $41.2 \%$ & $81.9 \%$ \\
& $(845)$ & $(113)$ & $(14)$ & $(972)$ \\
Moderate & $7.7 \%$ & $26.2 \%$ & $38.2 \%$ & $11.6 \%$ \\
& $(74)$ & $(51)$ & $(13)$ & $(138)$ \\
Severe & $4.1 \%$ & $15.9 \%$ & $20.6 \%$ & $6.5 \%$ \\
& $(39)$ & $(31)$ & $(7)$ & $(77)$ \\
\hline
\end{tabular}

Table 9 Grade of dysplasia (\%) and number of adenomas (601 patients)

\begin{tabular}{lllll}
\hline Grade & 1 & 2 & 3 & 4 \\
\hline Mild & 73 & 63 & 59 & 51 \\
Moderate & 13 & 20 & 24 & 24 \\
Severe & 14 & 17 & 17 & 25 \\
\hline
\end{tabular}

Table 10 Multiplicity and age (601 patients)

\begin{tabular}{lllll}
\hline & $<50 y r$ & $51-70 y r$ & $>70 y r$ & Total \\
\hline Single & $56.4 \%$ & $49.0 \%$ & $43.8 \%$ & $49.6 \%$ \\
& $(66)$ & $(190)$ & $(42)$ & $(298)$ \\
Multiple & $43.6 \%$ & $51.0 \%$ & $56.2 \%$ & $50.4 \%$ \\
& $(51)$ & $(198)$ & $(54)$ & $(303)$ \\
\hline
\end{tabular}

tological type becomes more villous severe dysplasia becomes more common (Table 8 ). This trend is similar to that shown in other studies. ${ }^{46}$

\section{SIZE AND GRADE OF DYSPLASIA}

The influence of the size of adenomas on grade of dysplasia shows a similar trend to that previously reported from this hospital. ${ }^{6}$ As the size of adenomas increases so does the grade of dysplasia in agreement with previous study. ${ }^{4517}$ Size is the simplest and most practical indicator and is closely related to grade of dysplasia.

\section{MULTIPLICITY OF ADENOMAS}

The numbers of adenomas per patient for this series in which there was total examination of the large bowel was $50 \%$ with one adenoma, $24 \%$ with two, $14 \%$ with three and $12 \%$ with four or more. Investigation of the relationship of size and number of adenomas per patient showed that with increasing number there is a trend towards a greater percentage of adenomas with severe dysplasia (Table 9). With increasing age of patient there is also a trend for the percentage of patients with multiple adenomas to increase (Table 10).

\section{Discussion}

Colorectal adenomas can be defined as well demarcated, circumscribed lumps of epithelial dysplasia (atypia) with or without a stalk, usually polypoid but occasionally flat, which can be categorised into three histological types: tubular, tubulovillous and villous. ${ }^{18}$ The histology of these three types of adenoma has been well documented, but it is important to remember that these are not clear cut categories, being only different manifestations of a spectrum of abnormal tissue architecture. ${ }^{19}$

The degree of dysplasia of adenomas can be graded subjectively into mild, moderate and severe, the latter being closest to invasive carcinoma. Severe dysplasia is used synonymously with carcinoma-insitu. Although there are differences the cellular features of dysplasia in adenomas have much in common with the dysplasia seen as a consequence of long-standing ulcerative colitis and the chronic colitis caused by Schistosoma japonica. ${ }^{2021}$ Similar changes of focal or diffuse epithelial dysplasia are seen in the stomach ${ }^{22}$ and in the squamous mucous membrane of the oesophagus. ${ }^{23}$ Moreover, it has been pointed out ${ }^{24}$ that the word "dysplasia" has general applicability in the description of histopathological precursor lesions for cancer in a variety of epithelial surfaces both within and without the gastrointestinal tract. Conceptually it now appears advantageous to think in terms of the dysplasiacarcinoma sequence in the colorectum rather than the polyp-cancer or adenoma-carcinoma sequence.

Kalus $^{25}$ reported that the incidence of severe dysplasia in adenomas (he used the term "carcinomain-situ") was $6.1 \%$ in patients with benign lesions only, whereas the incidence rose to $47 \%$ in adenomas associated with carcinoma in the same segment of the colon. From this result he concluded that the diagnosis of severe dysplasia in an adenoma should be followed by careful search for frank adenocarcinoma in any remaining colon. In another study of necropsy material in two different communities in Japan by Sato et $a^{26}$ it was shown that adenomas are more often found in a high colorectal cancer risk community (Akita-30\%) than in a low risk community (Miyagi-18.3\%). These authors also showed that the adenomas found in the high risk community (Akita) more often exhibited severe dysplasia than in the low risk community (Miyagi). These studies suggest that severe dysplasia in adenomas might be useful as a selective marker for increased colorectal cancer risk.

Hill $e t a^{27}$ described an hypothesis for the aetiology of colorectal cancer in which they suggested that three factors operated in the process of carcinogenesis. Factor E1 was considered to be the fac- 
tor which produces small adenomas. The second factor E2 makes the smaller adenomas become bigger. The third factor $\mathrm{C}$ induces carcinoma in a high proportion of large adenomas. This factor is considered to be ubiquitous and to play no part in determining the differences in the risk of developing carcinoma in large adenomas. Following this hypothesis, we suggest that patients who have small and only mildly dysplastic adenomas may be exposed to factor E1 but not E2 and these patients are considered to have a low cancer risk. On the other hand patients who have adenomas with severe dysplasia are considered to have intensified factor E2 and consequently a high cancer risk.

Our results have shown that the larger adenomas with severe dysplasia are mostly concentrated in the left colon and rectum, but particularly the sigmoid part. On the other hand, small adenomas with mild dysplasia showed a more or less even distribution throughout the large bowel. It would appear that the factor which produces small adenomas with mild dysplasia operates relatively evenly throughout the colorectum and that the factor which makes small adenomas larger and more dysplastic is particularly concentrated in the sigmoid part. Haenszel and Correa $^{28}$ reported that the ratio of sigmoid colon carcinoma to rectal carcinomas $(S / R)$ increases from low-risk countries to high-risk countries. In 1975 the same authors reported that the site of rectal carcinoma was higher in a high-risk community of New Orleans than in the low cancer risk community of Cali, Colombia. ${ }^{29}$ There are two other reports from the USA which show an increase in the ratio of colonic carcinomas to rectal carcinomas during the last 30 yr. $^{30}{ }^{31}$ Although most of the reports of surgically removed carcinomas in high cancer risk countries show a higher incidence of carcinomas in the recium than in the sigmoid colon, ${ }^{72-34}$ necropsy studies have shown that the percentage of sigmoid colon carcinomas is greater than that of rectal carcinomas $^{123336}$ possibly because the number of undiagnosed sigmoid colon carcinomas is greater than those of rectal carcinomas. ${ }^{34}$ Since it is probable that the true distribution of large bowel carcinomas is shown in the necropsy studies it can be concluded that in countries with a high colorectal cancer risk carcinomas are more frequently present in the sigmoid colon than in the rectum, which closely correlates with the site distribution of adenomas with severe dysplasia as reported here.

There are reports relating increased numbers of adenomas to increased cancer risk. ${ }^{637}$ For example, Muto et al reported that as the number of adenomas per patient increased so did the percentage of patients with invasive carcinoma. If the genesis of large bowel carcinoma is considered according to the hypothesis of Hill et al, ${ }^{27}$ it can be inferred that when the factor which produces adenomas (E1) is intensified, the number of adenomas per patient will increase. In his epidemiological study published in $1978,{ }^{38}$ Hill tabulated the prevalence of various factors among countries with various grades of cancer risk deduced from the incidence of adenomas and carcinomas. In this Table both factor E1 and E2 are present in high risk countries and both are normally absent in low risk countries. In other words these factors usually appear together. From this result we can deduce that if there are multiple adenomas present in patients where E1 is intensified, factor E2 would also be intensified, making some adenomas larger and more dysplastic. Our results on the relation between grades of dysplasia and the number of adenomas per patient support this theory. Patients with multiple adenomas tend to have a greater risk of developing severe dysplasia which suggests that these patients have a higher cancer risk than the patients with solitary adenumas. The evidence that the greater the number of adenomas per patient the greater the cancer risk is supported by the example of familial polyposis coli in which there are thousands of adenomas per patient, with an almost $100 \%$ risk of developing carcinoma.

It is well known that there is a higher colorectal cancer risk with increasing age. We have confirmed previous reports ${ }^{131739}$ of a relation between age and severe dysplasia which, although not statistically significant, demonstrates a trend. Persons over $70 \mathrm{yr}$ old are particularly prone to a high incidence of severe dysplasia and consequently can be considered to be those with the highest cancer risk. Table 10 also demonstrates the trend that as age increases the percentage of patients with multiple adenomas becomes greater.

Colorectal adenomas are common and most of them never become malignant. In other words the adenoma is a very dilute marker of increased colorectal cancer risk. The objective must be to search for more selective markers of especially high cancer risk by studying the histopathological features of adenomas. It is already well established that those $>10 \mathrm{~mm}$ diameter, tumours with a pronounced villous component and adenomas with severe dysplasia have the greatest malignant potential, but in this study evidence is presented which suggests that severe dysplasia per se may be the most selective marker of increased cancer risk and that this is closely linked with the site distribution of colorectal cancers, numbers of adenomas per patient, and increasing age. Severe dysplasia and multiple adenomas could be valuable markers for selecting from the total population of patients with adenomas those most deserving of close surveillance in 
follow-up cancer prevention programmes, but this could only be satisfactorily demonstrated by prospective studies.

The concentration of severely dysplastic adenomas in the left colon and rectum suggests that the short flexible fibreoptic colonoscope might prove to be especially valuable in the design of cancer detection and cancer prevention programmes because it is easier to use than the long instrument and theoretically should detect the majority of adenomas destined to become cancerous. Detection of lesions in the more proximal colon could be left to investigation by air contrast barium enema studies. A combination of these endoscopic and radiological techniques might prove to be the most effective screening procedure.

This research was made possible by grants to $F$ Konishi from the British Council and to BC Morson from the Cancer Research Campaign, for which we express our gratitude. We are also grateful to $\mathrm{Dr}$ HJR Bussey for invaluable advice, to $\mathrm{Dr}$ CB Williams and the staff of the Endoscopy Unit at St Mark's Hospital for their co-operation, to Mr Lloyd Soodeen for technical assistance, to $\mathrm{Mr}$ Nigel Hathaway of the Department of Medical Electronics at St Bartholomew's Hospital for processing the data, to Mr Bill Brackenbury for the microphotographs and to Miss DE Harwood for secretarial assistance.

\section{References}

' Williams CB. Diathermy-biopsy: a technique for the endoscopic management of small polyps. Endoscopy 1973;5:215-8.

${ }^{2}$ Morson BC. The pathogenesis of colorectal cancer. In: Bennington JL, ed, Major problems in pathology Vol 10. Philadelphia, London, Toronto: WB Saunders, 1978.

${ }^{3}$ Wychulis AR, Dockerty MB, Jackman RJ, Beahrs OH. Histopathology of small polyps of the large intestine. Surg Gynecol Obstet 1967;124:87-92.

${ }^{4}$ Ekelund G, Lindstrom C. Histopathological analysis of benign polyps in patients with carcinoma of the colon and rectum. Gut 1974;15:654-63.

${ }^{5}$ Kozuka S. Premalignancy of the mucosal polyp in the large intestine: I. Histologic gradation of the polyp on the basis of epithelial pseudostratification and glandular branching. Dis Colon Rectum 1975;18:483-93.

- Muto T, Bussey HJR, Morson BC. The evolution of cancer of the colon and rectum. Cancer 1975;36:2251-70.

${ }^{7}$ South Thames Cancer Registry. Report of the Executive Committee 1975/76 (incorporating statistics for 1972). London: 1976.

${ }^{8}$ Haenszel W, Correa P. Cancer of the large intestine: epidemiologic findings. Dis Colon Rectum 1973;16:371-7.

${ }^{9}$ Blatt LJ. Polyps of the colon and rectum: incidence and distribution. Dis Colon Rectum 1961;4:277-82.

${ }^{10}$ Chapman I. Adenomatous polypi of large intestine: incidence and distribution. Ann Surg 1963;157:223-6.

"Arminski TC, McLean DW. Incidence and distribution of adenomatous polyps of the colon and rectum based on 1000 autopsy examinations. Dis Colon Rectum 1964;7:249-61.
${ }^{12}$ Stemmermann GN, Yatani R. Diverticulosis and polyps of the large intestine. Cancer 1973;31:1260-70.

${ }^{13}$ Eide TJ, Stalsberg H. Polyps of the large intestine in Northern Norway. Cancer 1978;42:2839-48.

${ }^{14}$ Rickert RR, Auerbach O, Garfinkel L, Hammond EC, Frasca JM. Adenomatous lesions of the large bowel: an autopsy survey. Cancer 1979;43:1847-57.

is Enterline HT, Evans GW, Mercado-Lugo R, Miller L, Fitts Jr WT. Malignant potential of adenomas of colon and rectum. JAMA 1962;179:322-30.

${ }^{16}$ Welch JP, Welch CE. Villous adenomas of the colorectum. Am J Surg 1976;131:185-91.

${ }^{17}$ Silverberg SG. Focally malignant adenomatous polyps of the colon and rectum. Surg Gynecol Obstet 1970;131:103-14.

${ }^{18}$ World Health Organisation. Histological typing of intestinal tumours. In: Morson BC, Sobin LH, eds. International histological classification of tumours Vol 15. Geneva: WHO, 1976.

${ }^{19}$ Morson BC, Dawson IMP. Gastrointestinal pathology 2nd ed. Oxford: Blackwell Scientific Publications, 1979:654.

${ }^{20}$ Ming-Chai C, Jen-Chun H, P' Ei-Yu C et al. Pathogenesis of carcinoma of the colon and rectum in Schistosomiasis Japonica: a study of 90 cases. Chin Med J [Engl] 1965;84:513.

${ }^{21}$ Ming-Chai C, Chi-Yuan C, P'Ei-Yu C, Jen-Chun H. Evolution of colorectal cancer in schistosomiasis: transitional mucosal changes adjacent to large intestinal carcinoma in colectomy specimens. Cancer 1980;46:1661-75.

${ }^{22}$ Morson BC, Sobin LH, Grundmann E, Johansen A, Nagayo T, Serck-Hanssen A. Precancerous conditions and epithelial dysplasia in the stomach. J Clin Pathol 1980;33:711-21.

${ }^{23}$ Studies in relationship between epithelial dysplasia and carcinoma of the oesophagus compiled by co-ordinating groups for the research of oesophageal carcinoma, Honan province and the Chinese Academy of Medical Sciences. Chin Med J [Engl] 1975;1:110.

${ }^{24}$ Sheahan DG. Dysplasia: a pathologist's view of its general applicability. In: Winawer S, Schottenfeld D, Sherlock P, eds. Progress in cancer research and therapy: colorectal cancer, prevention, epidemiology and screening. Vol 13. New York: Raven Press, 1980:335-73.

${ }^{25}$ Kalus M. Carcinoma and adenomatous polyps of the colon and rectum in biopsy and organ tissue culture. Cancer 1972;30:972-82.

${ }^{26}$ Sato E, Ouchi A, Sassano N, Ishidate T. Polyps and diverticulosis of large bowel in autopsy population of Akita prefecture compared with Miyagi: high risk for colorectal cancer in Japan. Cancer 1976;37:1316-21.

${ }^{27}$ Hill MJ, Morson BC, Bussey HJR. Aetiology of adenomacarcinoma sequence in large bowel. Lancet 1978; i:245-7.

${ }^{28}$ Haenszel W, Correa P. Cancer of the colon and rectum and adenomatous polyps: a review of epidemiologic findings. Cancer 1971;28:14-24.

${ }^{29}$ Haenszel W, Correa P, Cuello C. Social class differences among patients with large bowel cancer in Cali, Colombia. $J$ Natl Cancer Inst 1975;54:1031-5.

${ }^{30}$ Axtell LM, Chiazze Jr L. Changing relative frequency of cancers of the colon and rectum in the United States. Cancer 1966;19:750-4.

${ }^{31}$ Snyder DN, Heston JF, Meigs JW, Flannery JT. Changes in site distribution of colorectal carcinoma in Connecticut, 1940 1973. Am J Dig Dis 1977;22:791-7.

${ }^{32}$ Gilbertsen VA. Adenocarcinoma of the large bowel: 1340 cases with 100 per cent follow up. Surgery 1959;46:1027-42.

${ }^{33}$ Shepherd JM, Jones JSP. Adenocarcinoma of the large bowel. $\mathrm{Br}$ J Cancer 1971;25:680-90.

${ }^{34}$ Berge T, Ekelund G, Mellner C, Pihl B, Wenckert A. Carcinoma of the colon and rectum in a defined population. Acta Chir Scand 1973; suppl 438:1-86.

${ }^{35}$ Helwig EB. The evolution of adenomas of the large intestine and their relation to carcinoma. Surg Gynecol Obstet 
1947;84:36-49.

${ }^{36}$ Ekelund G. On cancer and polyps of colon and rectum. Acta Pathol Microbiol Scand 1963;59:165-70.

${ }^{37}$ Rider JA, Kirsner JB, Moeller HC, Palmer WL. Polyps of colon and rectum. JAMA 1959;170:633.

${ }^{38}$ Hill MJ. Etiology of the adenoma-carcinoma sequence. In: Bennington $\mathrm{JL}$, ed. Major problems in pathology: the pathogenesis of colorectal cancer Vol 10. Philadelphia, London, Toronto: WB Saunders, 1978.
${ }^{39}$ Kozuka S, Nogaki M, Ozeki T, Masumori S. Premalignancy of the mucosal polyp in the large intestine: II. Estimation of the periods required for malignant transformation of mucosal polyp. Dis Colon Rectum 1975;18:494-500.

Requests for reprints to: Dr BC Morson, Pathology Department, St Mark's Hospital, City Road, London EC1V 2PS, England. 